(1)

CrossMark

\title{
Are smokers "hardening" or rather "softening"? An ecological and multilevel analysis across 28 European Union countries
}

\author{
Ariadna Feliu (10) ${ }^{1,2,3}$, Esteve Fernandez (10) ${ }^{1,2,3}$, Cristina Martinez $\mathbb{1}^{1,2,3}$ and \\ Filippos T. Filippidis $\mathbb{1}^{4}$
}

Affiliations: ${ }^{1}$ Tobacco Control Unit, WHO Collaborating Centre for Tobacco Control, Institut Català d'Oncologia-ICO, Barcelona, Spain. ${ }^{2}$ School of Medicine and Health Sciences, Campus de Bellvitge, Universitat de Barcelona, Barcelona, Spain. ${ }^{3}$ Tobacco Control Research Group, Institut d'Investigació Biomèdica de Bellvitge-IDIBELL, Barcelona, Spain. ${ }^{4}$ Dept of Primary Care and Public Health, School of Public Health, Imperial College London, London, UK.

Correspondence: Esteve Fernandez, Tobacco Control Unit, Institut Català d'Oncologia, Avinguda de la Granvia de L'Hospitalet 199-203, L'Hospitalet de Llobregat, 08908 Barcelona, Spain.

E-mail: efernandezQiconcologia.net

@ERSpublications

This study does not support the hardening hypothesis in the European Union, but suggests a softening of the smoking population. However, social inequalities in heavy smoking underline the need for interventions targeting smokers in vulnerable groups. http://bit.ly/2xfgM5v

Cite this article as: Feliu A, Fernandez E, Martinez C, et al. Are smokers "hardening" or rather "softening"? An ecological and multilevel analysis across 28 European Union countries. Eur Respir J 2019; 54: 1900596 [https://doi.org/10.1183/13993003.00596-2019].

\section{ABSTRACT}

Background: Tobacco control policies can reduce smoking prevalence. These measures may be less effective where smoking prevalence has significantly declined, as the remaining smokers have "hardened". Our aim was to empirically evaluate the "hardening hypothesis" at the population level in the European Union (EU) and explore factors associated with hardcore smoking.

Methods: We conducted two separate analyses in the EU using data on smoking from the Eurobarometer surveys (2009-2017, $\mathrm{n}=112745)$. 1) A panel-data fixed-effects linear regression to investigate changes over time in the percentage of hardcore smokers in relation to standardised smoking prevalence at the country level. 2) A multilevel logistic regression analysis with hardcore (daily smokers, $\geqslant 15$ cigarettes per day who have not attempted to quit in the last 12 months) or light $(<5$ cigarettes per day) smoking as the dependent variable and time as the main independent variable, controlling for individual and ecological variables.

Results: We studied 29010 current smokers (43.8\% hardcore smokers and $14.7 \%$ light smokers). The prevalence of hardcore smoking among adult smokers increased by 0.55 (95\% CI $0.14-0.96$ ) percentage points per each additional percentage point in the overall smoking prevalence. The odds of being a hardcore smoker increased over time and were higher in middle-aged males and people with financial difficulties, while the odds of being a light smoker significantly declined among females.

Conclusion: This study does not support the "hardening hypothesis" in the EU between 2009 and 2017, but suggests a softening of the smoking population. Existing tobacco control policies are likely to be suitable to further decrease smoking prevalence in Europe. 


\section{Introduction}

Tobacco is the largest preventable health hazard in the European Union (EU) [1]. Despite the decline in tobacco smoking prevalence over recent decades, Europe remains the region with the highest smoking prevalence among adults (28\%: males 38\% and females 19\%) and has some of the highest prevalence of tobacco use by adolescents [2].

To address the tobacco epidemic, the EU ratified the World Health Organization Framework Convention on Tobacco Control [3] and developed a Tobacco Product Directive, which was revised in 2014 [4]. Subsequently, all EU Member States have implemented key tobacco control policies [5]; however, large differences still exist in the implementation and enforcement levels of tobacco control policies across the $\mathrm{EU}[6,7]$.

Established tobacco control policies have been shown to reduce smoking prevalence $[6,8]$. However, it has been suggested that tobacco control measures are less effective in countries where a significant decline in smoking prevalence has been observed, as the population of smokers becomes more "hardened" [9]. This is known as the "hardening hypothesis", which proposes that when the prevalence of smoking decreases, smokers who quit first are those less dependent and hence the remaining smokers in the population are "hardcore smokers", including inveterate smokers with high consumption, high cigarette dependence and low motivation to quit $[10,11]$. The confirmation of the hardening hypothesis in a population would have important implications since this group may represent a difficult-to-reach, special population, for who tobacco control efforts may need to be specifically tailored [12]. Thus, the feasibility of tobacco endgame strategies, which suggest moving beyond tobacco control towards a tobacco-free future [13], would be compromised, given that they would be effective only assuming a transition from combustible tobacco to alternative forms of nicotine delivery systems [14].

The evidence is not yet conclusive to support or refute the hardening hypothesis [15]. A few previous studies have supported the hardening hypothesis; however, they were either cross-sectional analyses based on ecological data [16], individual-level data from a single country [17] with their known limitations [9] or meta-analyses of clinical trials that only include selected subpopulations of patients [10]. Other studies reject the hardening hypothesis $[10,18-23]$ and suggest that smokers could be softening instead $[10,11$, 24]. Most of these studies have used data from one country at a time, except for two studies that have addressed this question jointly in several European countries together with the USA [10, 11]; however, none has systematically addressed this question across all $28 \mathrm{EU}$ Member States. The EU provides a suitable context to explore this question, as there have been substantial declines in smoking prevalence over the past 10 years, in a background of common regulations [4], but also considerable variation among EU Member States.

The aims of this study were to empirically evaluate whether the hardening hypothesis can be confirmed at the population level in the $28 \mathrm{EU}$ Member States, and to analyse the determinants of hardcore and light smoking considering both individual and contextual country-level characteristics.

\section{Methods}

We conducted a study in the $28 \mathrm{EU}$ Member States by performing two separate analyses: one with individual and contextual data, and one with ecological data. We used data on smoking from waves 72.3 (2009), 77.1 (2012), 82.4 (2014) and 87.1 (2017) of the Eurobarometer survey [25-28]. Eurobarometer is a cross-sectional study of representative samples of the adult population ( $\geqslant 15$ years old) conducted by the European Commission. The fieldwork was conducted in October 2009 (n=27 788), February-March 2012 $(\mathrm{n}=26751)$, November-December $2014 \quad(\mathrm{n}=27801)$ and March $2017 \quad(\mathrm{n}=27901)$. Samples are independently selected in each wave. Each Eurobarometer survey uses a random, multistage sampling method and post-stratification sample weighting is applied independently in each wave. As a result, samples are representative of the population by age, sex and area of residence, both at a country level and at the EU level.

\section{Data sources and variables}

Tobacco consumption

Smoking prevalence was estimated from respondents answering "I currently smoke" to the question "Regarding smoking cigarettes, cigarillos, cigars or a pipe which of the following applies to you?" Smoking prevalence in 2009 was obtained from the proportion of respondents who gave the answer "I smoke at the present time" to the same question. We also calculated the prevalence of ex-smokers and never-smokers using the proportion of respondents that answered "I used to smoke but now I have stopped" and "I have never smoked", respectively. 
All smokers were also asked to report whether they smoke manufactured and roll-your-own cigarettes daily or occasionally, how many cigarettes they smoke per day, and whether they had ever tried to quit ("yes, in the last 12 months", "more than a year ago" or "no, never").

"Hardcore smokers" were defined as 1) current smokers, 2) who smoked manufactured cigarettes or roll-your-own daily, 3) who smoked on average at least 15 cigarettes per day and 4) who reported not having made any quit attempt in the last 12 months. There is no universally accepted definition of hardcore smokers [15]; therefore, we conducted a sensitivity analysis including an additional criterion to our definition: age $\geqslant 26$ years, which reflects the assumption that younger smokers may not have reached a stable level of average daily consumption or solidified their intentions regarding quitting [12, 24, 29]. We defined "light smokers" as occasional or daily current smokers who reported smoking less than 5 cigarettes per day [30].

\section{Tobacco control policies}

The Tobacco Control Scale (TCS; www.tobaccocontrolscale.org) is a scoring system developed by a panel of experts to quantify the national-level implementation of tobacco control policies. The six components of the TCS are: price (30 points), public place bans (22 points), public information campaigns spending (15 points), advertising bans (13 points), health warnings (10 points) and treatment (10 points). The score increases with the strength of tobacco control policies up to a possible maximum of 100 points, indicating a full implementation for all strategies considered. For each year, we used the most recent TCS report published before the year of the survey (TCS for 2007, 2010, 2013 and 2016).

Gross domestic product per capita

We obtained the gross domestic product (GDP) per capita in 2009, 2012, 2014 and 2017 from Eurostat (the official statistical office of the EU) [31].

\section{Sociodemographic data}

We also used information about sex (male and female), age (15-24, 25-34, 35-44, 45-54, 55-64 and $\geqslant 65$ years), difficulties in paying bills in the last 12 months (most of the time, from time to time and almost never or never), age when they stopped full-time education ( $\leqslant 15,16-19$ and $\geqslant 20$ years), marital status (married, single, divorced and other) and type of community (rural area or village, small or middle town and large town) as collected by Eurobarometer.

\section{Statistical analysis}

We calculated the age- and sex-standardised prevalence of never-, ex- and current smokers and hardcore and light smokers in each EU Member State (2009, 2012, 2014 and 2017) by means of the direct method of standardisation using the European population of 2013 as the standard population.

Time trends of standardised prevalence of smoking status (never-, ex-, current, hardcore and light smokers) separately by each EU Member State were graphically described (2009-2017).

We conducted an ecological analysis with the country as the unit of analysis to assess the association between the relative change in the prevalence of hardcore or light smokers among current smokers (dependent variables) and the relative change in smoking prevalence (independent variable) from 2009 to 2017. We conducted an analysis in the total population, and by sex, by means of scatter plots and Spearman rank correlation coefficients $\left(\mathrm{r}_{\mathrm{sp}}\right)$ with the corresponding $95 \%$ confidence intervals. The relative change was calculated as a percentage of the prevalence in the earlier period. We used relative and not absolute change to account for the baseline differences between EU Member States.

We conducted a panel-data fixed-effects linear regression analysis both in the total population and stratified by sex, with the proportion of hardcore smokers among current smokers as the dependent variable and smoking prevalence as the main independent variable to investigate the percentage of hardcore smokers in relation to smoking prevalence. We adjusted the panel-data regression for time to account for underlying trends and the total TCS score of each EU Member State. GDP per capita was not included in the model as it did not improve the fit of the model. The fixed-effects specification accounts for time-invariant unobserved factors within each country [32].

We conducted a multilevel logistic regression analysis with two levels of analysis (individual and country) to account for clustering of observations within countries to assess the association of being a hardcore or a light smoker (dependent variable) with time (continuous variable, by calendar year), age, sex, difficulties in paying bills, marital status, education and type of community (independent variables) adjusting for TCS score (per 10 points change) and GDP per capita (per EUR 1000 change). We used Akaike and Bayesian information criteria to determine the optimal specification of the logistic regression model. We observed a 
statistically significant effect modification between time and education for hardcore smokers and between time and sex for light smokers; therefore, we stratified the analysis by education and sex, respectively.

A sensitivity analysis was conducted with the alternative definition of hardcore smokers using age $\geqslant 26$ years for the main analyses.

\section{Results}

Our sample had 29010 current smokers (26.6\%) from which $43.8 \%$ were hardcore smokers and $14.7 \%$ were light smokers across the four waves of the Eurobarometer surveys. By age group, young smokers (1524 years old) had the lowest rate of hardcore smokers (27.2\%), while middle-aged smokers (45-54 years old) had the highest rate of hardcore smokers (50.6\%) (supplementary table S1).

In the EU, as a whole, age- and sex-standardised smoking prevalence decreased from $28.7 \%$ in 2009 to $26.5 \%$ in 2017 , while hardcore smoking increased from $36.7 \%$ to $41.6 \%$ and light smoking decreased from $19.2 \%$ to $16.9 \%$ among current smokers (figure 1). In most countries where the prevalence of hardcore smokers has decreased, light smokers have increased and vice versa, although there was variation among EU Member States (figures 1 and 2).

At the ecological level, we explored the association between the relative change in hardcore and light smoking prevalence among current smokers and the relative change in smoking prevalence from 2009 to 2017. A decreasing smoking prevalence was associated with a decreasing proportion of hardcore smokers among all current smokers $\left(r_{s p}=0.432, p=0.019\right.$; males: $r_{s p}=0.270, p=0.158$; females: $\left.r_{s p}=0.366, p=0.051\right)$ (figure 3a) and an increasing prevalence of light smokers $\left(r_{s p}=-0.334, p=0.076 ;\right.$ males: $r_{s p}=-0.289$, $\mathrm{p}=0.128$; females: $\mathrm{r}_{\mathrm{sp}}=-0.044, \mathrm{p}=0.819$ ) (figure $3 \mathrm{~b}$ ). The sensitivity analysis with the alternative definition of hardcore smokers showed a correlation in the same direction $\left(\mathrm{r}_{\mathrm{sp}}=0.253, \mathrm{p}=0.185\right)$, although it did not reach statistical significance.

The panel-data regression analysis showed that per each additional percentage point in smoking prevalence, the prevalence of hardcore smoking increased by 0.55 percentage points ( 0.32 percentage points in males and 0.72 percentage points in females). The prevalence of light smokers decreased by 0.30 percentage points for each percentage point increase in overall smoking prevalence, adjusting for time and TCS scores (table 1). The sensitivity analysis showed similar results with an increase of 0.29 percentage points in the prevalence of hardcore smokers per each additional percentage point in the prevalence of smoking in the general population, although the association was not statistically significant.

The multilevel logistic regression analysis showed a significant interaction between time (by calendar year) and education when assessing hardcore smoking as the dependent variable and between time and sex when analysing light smoking as the dependent variable. Therefore, all analyses are presented stratified by education level and sex.

As shown in table 2, the odds of being a hardcore smoker increased over time among all education groups. Middle-aged individuals (35-64 years old) were the most likely to be hardcore smokers. Among the higher educated groups, we observed that individuals having some or many difficulties in paying bills had also higher odds of being hardcore smokers. Finally, among individuals who stopped full-time education when they were $\geqslant 20$ years old, being divorced, separated or widowed also increased the odds of hardcore smoking. Conversely, odds of hardcore smoking were lower for females compared with males in all groups and, in the lowest educated group, it also decreased among residents of countries with a higher TCS score (OR 0.88, 95\% CI 0.81-0.95). The sensitivity analysis showed that the odds of hardcore smoking did not increase over time in any group, but it showed similar results for age, sex and difficulties in paying bills.

The odds of being a light smoker did not significantly change over time among males and declined over time among females (OR 0.98, 95\% CI 0.96-0.99). Consistent with the findings about hardcore smoking, middle-aged individuals and those having difficulties in paying bills had lower odds of being light smokers. Males and females with higher education were more likely to be light smokers compared with those with low or no formal education. In males, the odds of being a light smoker were also higher in countries with a higher GDP and higher TCS scores (table 2).

\section{Discussion}

Main results

Our study shows that hardcore smoking prevalence is not increasing in those EU Member States where smoking prevalence is declining. Otherwise, contrary to the "hardening hypothesis", it is the prevalence of light smoking that is increasing. Moreover, our findings show that the odds of being a hardcore smoker are higher among middle-aged males who had difficulties in paying bills in the last 12 months and lower 

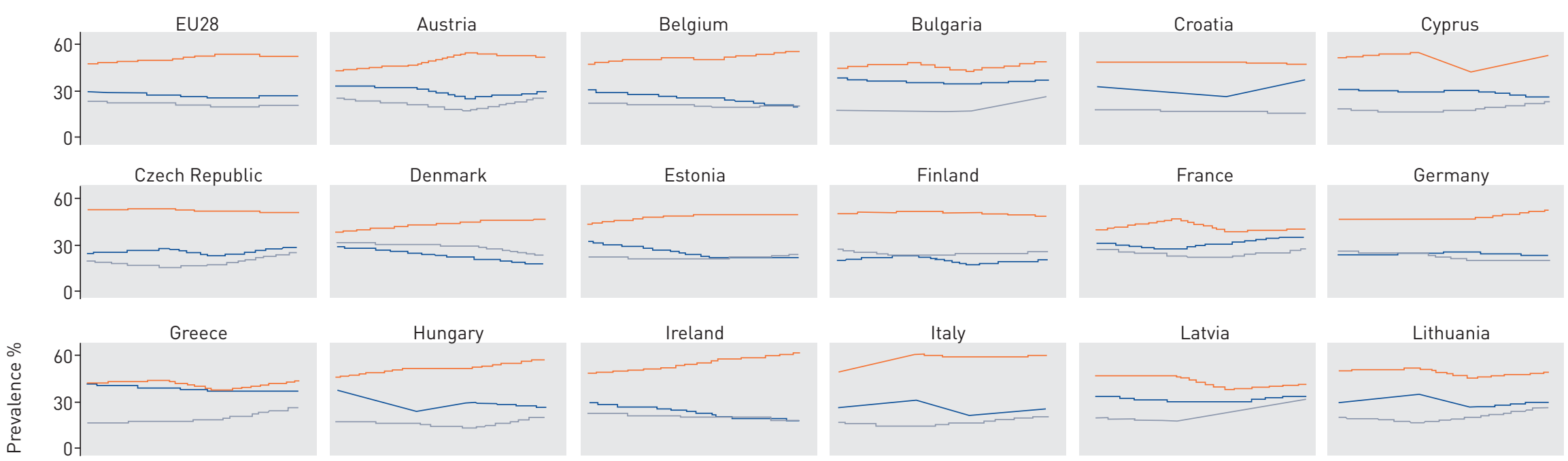

Finland
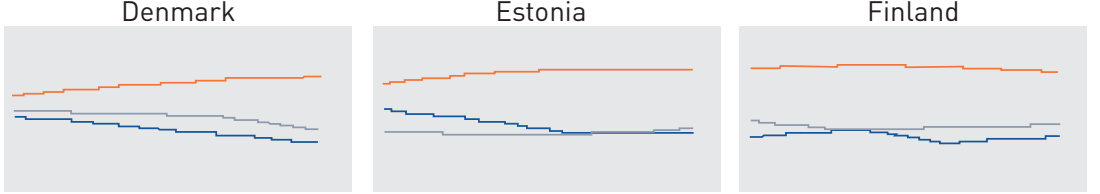

France

Germany
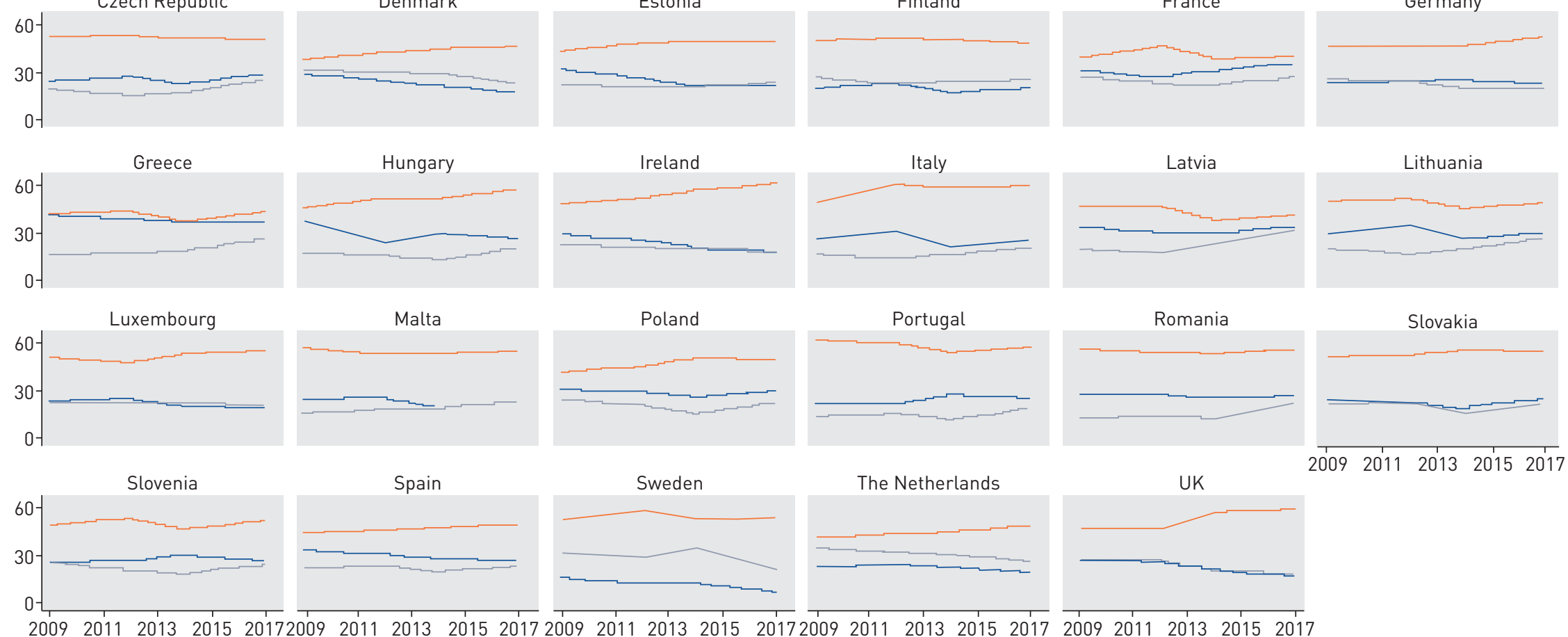

20092011201320152017

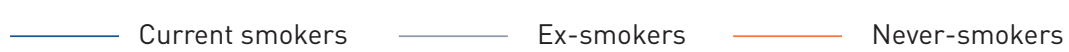

FIGURE 1 Time trends of prevalence of current smokers, ex-smokers and never-smokers among the population in the 28 European Union Member States (EU28) from 2009 to 2017. 


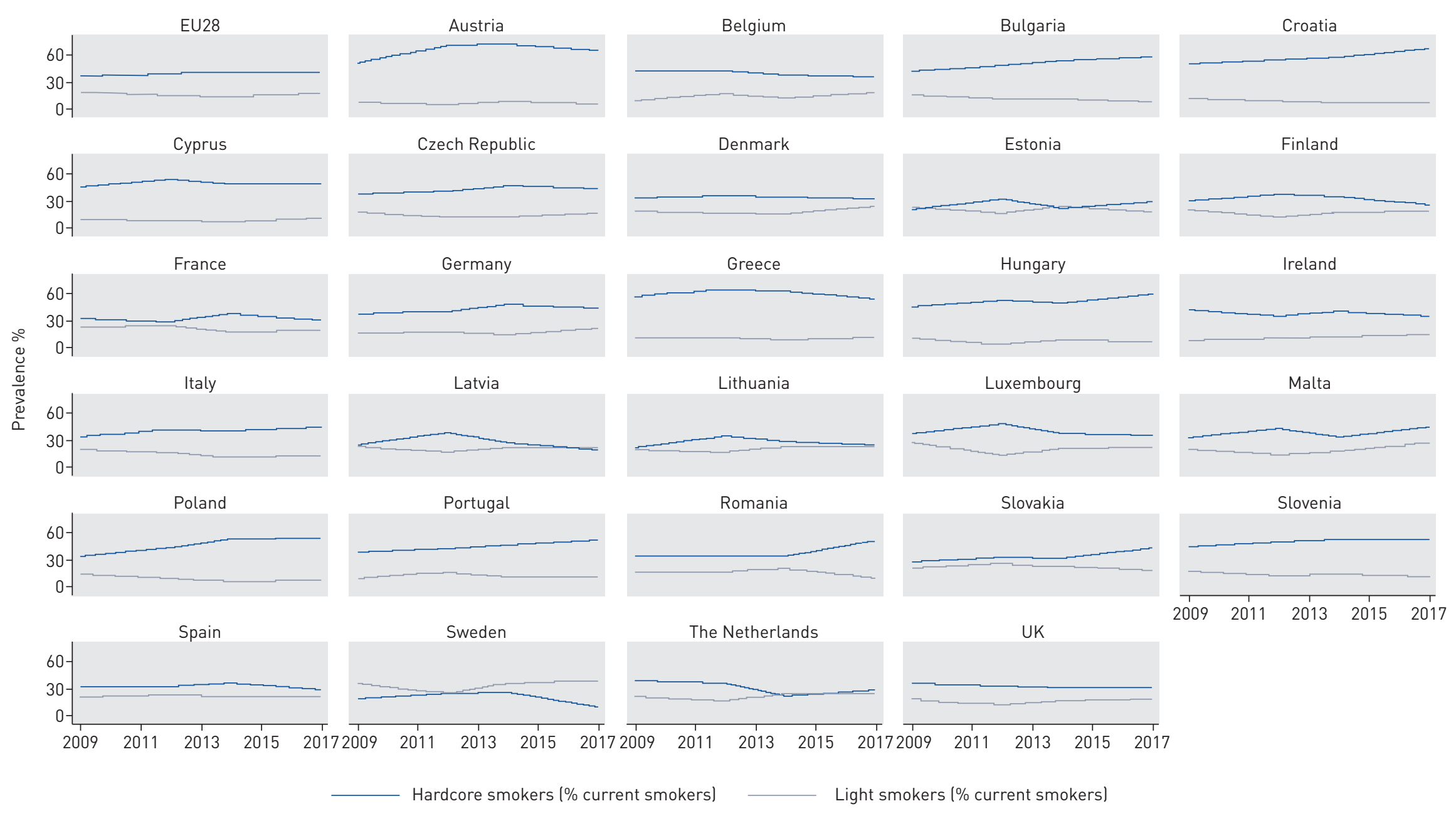

FIGURE 2 Time trends of prevalence of hardcore and light smoking among current smokers in the 28 European Union Member States (EU28) from 2009 to 2017. 
a)

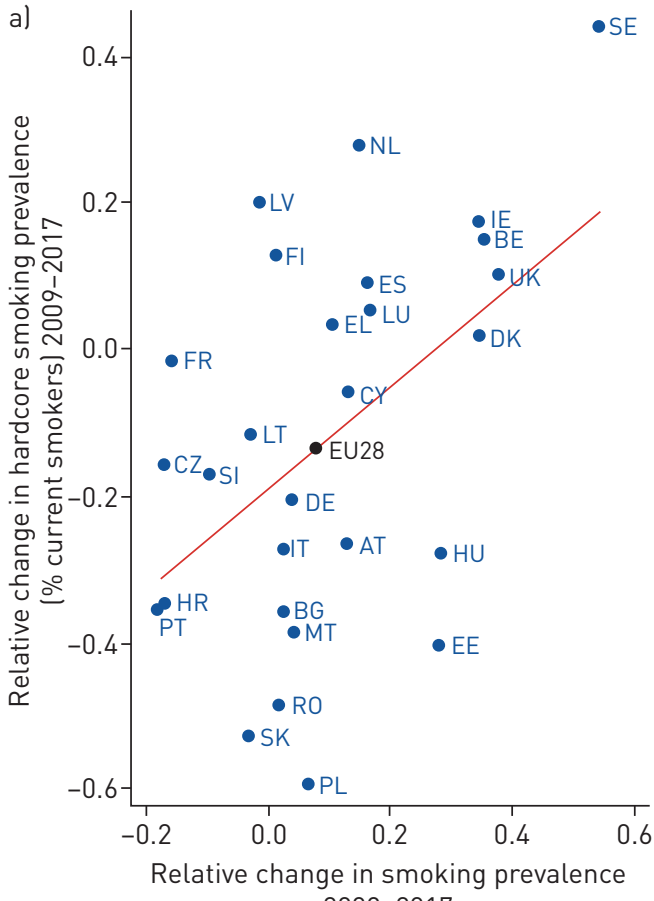

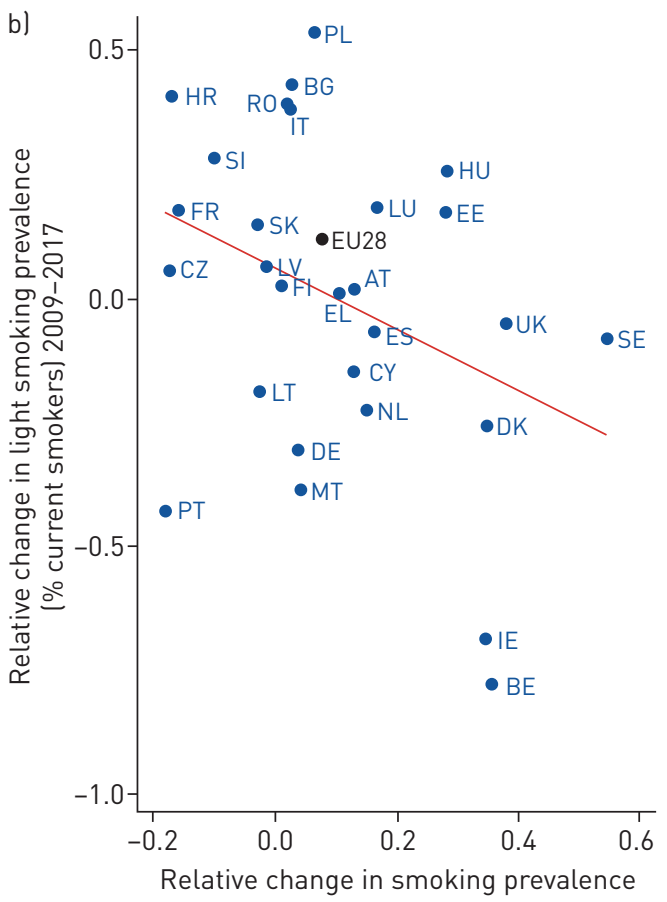

2009-2017

FIGURE 3 Correlation between relative changes in a) hardcore smoking and b) light smoking prevalence among current smokers and in smoking prevalence from 2009 to 2017. AT: Austria; BE: Belgium; BG: Bulgaria; HR: Croatia; CY: Cyprus; CZ: Czech Republic; DK: Denmark; EE: Estonia; FI: Finland; FR: France; DE: Germany; EL: Greece; HU: Hungary; IE: Ireland; IT: Italy; LV: Latvia; LT: Lithuania; LU: Luxembourg; MT: Malta; PL: Poland; PT: Portugal; RO: Romania; SK: Slovakia; SI: Slovenia; ES: Spain; SE: Sweden; NL: The Netherlands; UK: United Kingdom; EU28: overall average in the 28 European Union Member States. Relative changes in prevalence were calculated as a percentage of the prevalence in the earlier period. The red line shows the fitted values.

in countries with stronger tobacco control policies. Hardcore smoking was also associated with marital status and education.

\section{Interpretation of the results}

Smoking prevalence has decreased overall over time in the EU; however, in some countries it has increased (e.g. in France and Croatia) [6]. In these countries, the prevalence of hardcore smokers has also increased,

TABLE 1 Panel-data linear regression analysis for hardcore and light smoking prevalence as a function of smoking prevalence, time (year) and Tobacco Control Scale (TCS): overall and stratified by sex

Hardcore smoking 1 year change

Light smoking 1 year change

$\begin{array}{lcc}\text { Total } & & \\ \text { Smoking prevalence } & 0.550 *(0.137-0.963) & -0.297 *(-0.547--0.044) \\ \text { Year } & 0.664 *(0.277-1.052) & -0.084(-0.322-0.153) \\ \text { TCS } & -0.222(-0.495-0.051) & 0.149(-0.018-0.317) \\ \text { Males } & & \\ \text { Smoking prevalence } & 0.320(-0.092-0.732) & -0.176(-0.434-0.082) \\ \text { Year } & 0.616 *(0.123-1.109) & -0.039(-0.348-0.270) \\ \text { TCS } & -0.158(-0.499-0.184) & 0.184(-0.031-0.398) \\ \text { Females } & & \\ \text { Smoking prevalence } & 0.717 *(0.162-1.273) & -0.164(-0.607-0.279) \\ \text { Year } & 0.627 *(0.105-1.149) & -0.035 *(-0.451-0.381) \\ \text { TCS } & -0.251(-0.633-0.131) & 0.070(-0.235-0.374)\end{array}$

Data are presented as $\beta(95 \% \mathrm{CI})$. $\beta$ coefficients represent the percentage point change per each additional percentage point in smoking prevalence. ${ }^{*}: \mathrm{p}<0.05$. 
TABLE 2 Multilevel logistic regression analysis stratified by age when stopped full-time education for hardcore smoking and by sex for light smoking

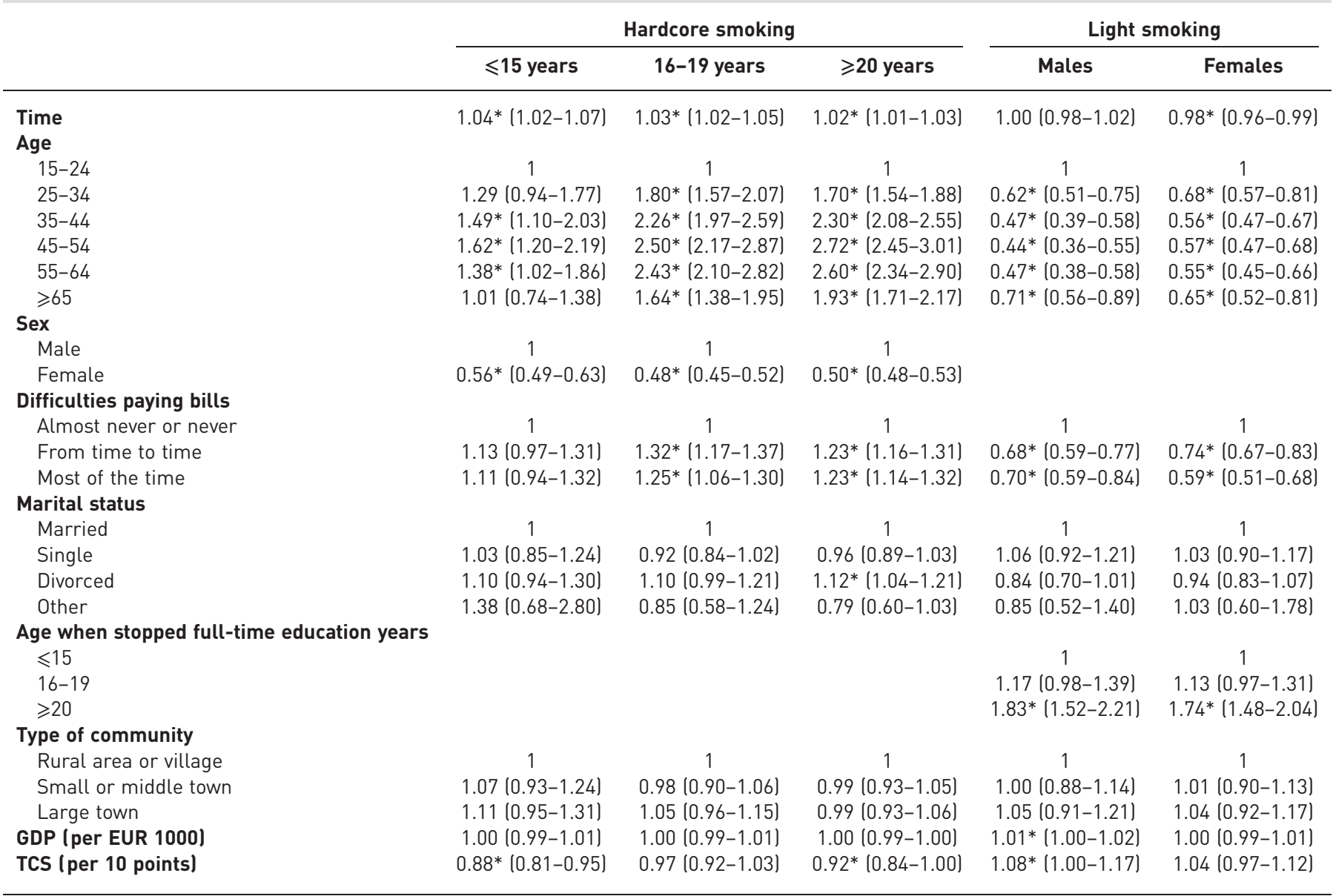

Data are presented as OR (95\% CI). GDP: gross domestic product; TCS: Tobacco Control Scale. *: p<0.05.

except for Latvia, where the prevalence increases in young cohorts (and mainly in females) who are less likely to become hardcore smokers in the short term. Our results suggest that, despite an overall increase in hardcore smoking prevalence, smokers in the EU are not hardening since hardcore smoking is decreasing and not increasing for each percentage point decrease in smoking prevalence. These results are in line with previous cross-sectional studies conducted in Europe that concluded that smoking prevalence was correlated to a higher Heavy Smoking Index and number of cigarettes smoked per day [10, 11].

European countries are at different stages of the tobacco epidemic based on the comparative levels of smoking prevalence and smoking-attributed mortality in males and females [33]. Most Eastern European countries are at stage 3 , which involves a flattening or downturn of male smoking prevalence with some convergence of smoking prevalence in both sexes and a steep increase of deaths attributable to smoking, with the rest of the countries at late stages 3 and 4 where, although prevalence is decreasing, smoking-attributable mortality continues to rise. Hereto, our analysis was stratified by sex to account for such differences, as Gallus et al. [34] suggested that countries at an earlier stage of the epidemic had a relatively high male-to-female smoking prevalence ratio. Our findings showed that in females the relation between increased smoking prevalence and higher hardcore smoking prevalence was stronger than in males despite the fact that females are already at advanced stages of the epidemic in high-income countries and even though the uptake of smoking among females is generally delayed compared with males [33]. Consistent with this, FERnÁndeZ et al. [10] observed that the relation between dependence and smoking prevalence was higher in females.

Despite an overall increase in the prevalence of hardcore smokers, our findings do not support the hardening hypothesis in the EU at a population level. Instead, the increase of light smoking among smokers implies a softening of the smoking population. This softening of the smoking population suggests 
that current tobacco control policies (e.g. smoke-free policies, tobacco taxation and advertising bans) have been effective not only in motivating light smokers to quit smoking, but also in influencing hardcore smokers to quit smoking or to reduce their daily cigarette consumption $[6,11,24]$. Other explanations could be that social denormalisation of smoking over time has fuelled quitting across the smoking population [24] or that light smokers, who are less addicted to nicotine, continue to smoke because of psycho-social factors rather than a physical addiction [10].

In addition, at an individual level, our findings suggest that the odds of hardcore smoking in the EU have increased over time after adjusting for sociodemographic and environmental factors. However, these results have not accounted for the changes in smoking prevalence and therefore should not be interpreted as evidence suggesting hardening [35].

Both hardcore and light smoking are associated with tobacco control policies, as the stronger the implementation, the lower the odds of hardcore smoking. Our results are consistent with a previous study also conducted in the EU that concluded that higher tobacco control efforts were correlated with higher quit ratios (percentage ex-smokers over ever-smokers) [6]. Disaggregating the effects of individual tobacco control policies was beyond the scope of this analysis, but future analyses could provide more insight into the issue.

Moreover, hardcore and light smoking can be associated to individual socioeconomic and demographic characteristics. Hardcore smoking was more prevalent among males, 35-64 years old, lower educated groups and individuals with more difficulties in paying bills. Conversely, light smoking was more frequent in females and higher educated individuals. These results are consistent with previous studies that also observed that smokers today belong to more deprived population groups than in the past [29, 36]. Therefore, regardless of whether the population of smokers is hardening or not, the social gradient in heavy smoking highlights the socioeconomic inequalities and the increased burden of smoking-related diseases among people in low socioeconomic groups [37]. To increase health equity, tobacco control policies should be tailored to subgroups of heavy smokers (including socially deprived and psychiatric distressed smokers [38]) to successfully continue softening the population of smokers.

\section{Limitations and strengths}

Although we analysed data from 28 EU Member States that allowed us to detect time trends across the EU, our ecological analyses were essentially based on a relatively small sample. EU Member States differ in several social, cultural and other factors, such as the stage of the tobacco epidemic [33]. Our efforts to account for differences across countries included stratifying analyses by sex since countries at an earlier stage of the epidemic present a higher male-to-female smoking prevalence ratio [34], as well as using a fixed-effects specification for our panel regression to control for unobserved country-level factors that may influence the results.

Our study might have overestimated the prevalence of hardcore smokers compared with previous studies, as we could not include a measure of nicotine dependence $[39,40]$ nor long-term smoking history (being a smoker for at least 5 years) of current smokers that are frequently used criteria as the Eurobarometer survey did not record this information in all four waves. However, to account for this possible limitation we conducted a sensitivity analysis including only smokers at least 26 years old [24, 29]. Moreover, we used secondary data from the smoking supplement of Eurobarometer, which is a periodic survey to monitor smoking indicators in the EU but lacks detailed information on other participant's characteristics, including factors potentially related to smoking and quit attempts. The use of self-reported data from questionnaires could be a source of bias, although self-reports on smoking status have acceptable validity [41].

Our study is the first to systematically approach the hardening hypothesis in all of the EU Member States, which are subject to common regulations, and to introduce a longitudinal perspective to this approach, including data from four cross-sectional surveys with consistent methods across countries and over time.

\section{Conclusions}

In conclusion, our study does not support the "hardening hypothesis" in the EU between 2009 and 2017, but rather suggests a softening of the smoking population over this period. These findings indicate that existing tobacco control policies may be suitable to further decrease smoking prevalence in Europe as we gradually move towards endgame strategies. However, social inequalities in heavy smoking underline the need for tailored interventions targeting smokers in vulnerable socioeconomic groups who may find it more difficult to quit or reduce smoking $[35,36]$.

Author contributions: Study design: A. Feliu, F.T. Filippidis and E. Fernandez. Collected data and prepared database for analysis: A. Feliu and F.T. Filippidis. Contributed to strategy of analysis: A. Feliu, F.T. Filippidis and E. Fernandez. Analysed data: A. Feliu. Interpreted data results: A. Feliu, F.T. Filippidis, C. Martinez and E. Fernandez. Drafted 
manuscript A. Feliu. Critically revised manuscript: all authors. Approved final manuscript version: all authors. Guarantors: E. Fernandez and F.T. Filippidis.

Conflict of interest: None declared.

Support statement: A. Feliu, C. Martinez and E. Fernandez were supported by the Ministry of Research and Universities from the Government of Catalonia (2017SGR319). A. Feliu has received financial support through the "Fundació Pedro I Pons" grant from the University of Barcelona, Barcelona, Spain. E. Fernandez was also supported by the Instituto de Salud Carlos III, Government of Spain, co-funded by the European Regional Development Fund (FEDER) (INT16/00211 and INT17/00103). C. Martinez was also supported by the Instituto de Salud Carlos III, Government of Spain, co-funded by the FEDER (INT17/00116) and Ministry of Health from the Government of Catalonia (PERIS 9015-586920/2017). Funding information for this article has been deposited with the Crossref Funder Registry.

\section{References}

1 European Commission. Special Eurobarometer 429: Attitudes of Europeans Towards Tobacco and Electronic Cigarettes. 2015. http://ec.europa.eu/public_opinion/archives/ebs/ebs_429_en.pdf Date last accessed: November 10, 2018.

2 World Health Organization. Tobacco. Data and Statistics. www.euro.who.int/en/health-topics/disease-prevention/ tobacco/data-and-statistics Date last accessed: November 10, 2018.

3 World Health Organization. WHO Framework Convention on Tobacco Control. 2005. www.who.int/tobacco/ framework/WHO_FCTC_english.pdf Date last accessed: February 18, 2019.

4 European Commission. Revision of the Tobacco Products Directive. 2014. http://ec.europa.eu/health/tobacco/ products/revision/index_en.htm Date last accessed: February 14, 2019.

5 Martínez-Sánchez JM, Fernández E, Fu M, et al. Smoking behaviour, involuntary smoking, attitudes towards smoke-free legislations, and tobacco control activities in the European Union. PLoS One 2010; 5: e13881.

6 Feliu A, Filippidis FT, Joossens L, et al. Impact of tobacco control policies on smoking prevalence and quit ratios in 27 European Union countries from 2006 to 2014. Tob Control 2019; 28: 101-109.

7 Bosdriesz JR, Willemsen MC, Stronks K, et al. Patterns of tobacco control policy progress in 21 European countries. Tob Regul Sci 2015; 1: 254-264.

8 International Agency for Research on Cancer. Evaluating the Effectiveness of Smoke-free Policies. 2009. https:// www.iarc.fr/wp-content/uploads/2018/07/handbook13.pdf Date last accessed: November 10, 2018.

9 Docherty G, McNeill A. The hardening hypothesis: does it matter? Tob Control 2012; 21: 267-268.

10 Fernández E, Lugo A, Clancy L, et al. Smoking dependence in 18 European countries: hard to maintain the hardening hypothesis. Prev Med 2015; 81: 314-319.

11 Kulik MC, Glantz SA, Francisco S. The smoking population in the USA and EU is softening not hardening. Tob Control 2017; 25: 470-475.

12 Emery S, Gilpin EA, Ake C, et al. Characterizing and identifying "hard-core" smokers: implications for further reducing smoking prevalence. Am J Public Health 2000; 90: 387-394.

13 McDaniel PA, Smith EA, Malone RE. The tobacco endgame: a qualitative review and synthesis. Tob Control 2016; 25: 594-604.

14 Chapman S, Wakefield MA. Large-scale unassisted smoking cessation over 50 years: lessons from history for endgame planning in tobacco control. Tob Control 2013; 22: i33-i35.

15 Ip DT, Cohen JE, Bondy SJ, et al. Do components of current "hardcore smoker" definitions predict quitting behaviour? Addiction 2012; 107: 434-440.

16 Fagerström K, Furberg H. A comparison of the Fagerström Test for Nicotine Dependence and smoking prevalence across countries. Addiction 2008; 103: 841-845.

17 Docherty G, McNeill A, Gartner C, et al. Did hardening occur among smokers in England from 2000 to 2010? Addiction 2014; 109: 147-154.

18 Edwards R, Tu D, Newcombe R, et al. Achieving the tobacco endgame: evidence on the hardening hypothesis from repeated cross-sectional studies in New Zealand 2008-2014. Tob Control 2017; 26: 399-405.

19 Azagba S. Hardcore smoking among continuing smokers in Canada 2004-2012. Cancer Causes Control 2015; 26 : 57-63.

20 Smith PH, Rose JS, Mazure CM, et al. What is the evidence for hardening in the cigarette smoking population? Trends in nicotine dependence in the U.S., 2002-2012. Drug Alcohol Depend 2014; 142: 333-340.

21 Pierce JP, Messer K, Cowling DW, et al. Prevalence of heavy smoking in California and the United States, 19652007. JAMA 2011; 305: 1106-1112.

22 O'Connor RJ, Giovino GA, Kozlowski LT, et al. Changes in nicotine intake and cigarette use over time in two nationally representative cross-sectional samples of smokers. Am J Epidemiol 2006; 164: 750-759.

23 Fu M, Martinez-Sanchez JM, Perez-Rios M, et al. A comparison of the Fagerstrom Test for Nicotine Dependence and smoking prevalence across countries: updated data from Spain. Addiction 2009; 104: 326-327.

24 Bommelé J, Nagelhout GE, Kleinjan M, et al. Prevalence of hardcore smoking in the Netherlands between 2001 and 2012: a test of the hardening hypothesis. BMC Public Health 2016; 16: 1-7.

25 European Commission. Special Eurobarometer 332: Tobacco. 2014. http://data.europa.eu/euodp/en/data/dataset/ S790_72_3_EBS332 Date last accessed: February 18, 2019.

26 European Commission. Special Eurobarometer 458: Attitudes of Europeans Towards Tobacco and Electronic Cigarettes. 2017. http://data.europa.eu/euodp/en/data/dataset/S2146_87_1_458_ENG Date last accessed: February $18,2019$.

27 European Commission. Special Eurobarometer 429: Attitudes of Europeans Towards Tobacco. 2015. http://data. europa.eu/euodp/en/data/dataset/S2033_82_4_429_ENG Date last accessed: February 18, 2019.

28 European Commission. Special Eurobarometer 385: Attitudes of Europeans Towards Tobacco. 2014. http://data. europa.eu/euodp/en/data/dataset/S1060_77_1_EBS385 Date last accessed: February 18, 2019.

29 Augustson EM, Barzani D, Finney Rutten LJ, et al. Gender differences among hardcore smokers: an analysis of the tobacco use supplement of the current population survey. J Women's Health 2008; 17: 1167-1173. 
30 Li X, Loukas A, Perry CL. Very light smoking and alternative tobacco use among college students. Addict Behav 2018; 81: 22-25.

31 European Commission. Eurostat. http://ec.europa.eu/eurostat/about/overview Date last accessed: March 19, 2018.

32 Bartolucci F, Belotti F, Peracchi F. Testing for time-invariant unobserved heterogeneity in generalized linear models for panel data. J Econom 2015; 184: 111-123.

33 Thun M, Peto R, Boreham J, et al. Stages of the cigarette epidemic on entering its second century. Tob Control 2012; 21: 96-101.

34 Gallus S, Lugo A, La Vecchia C, et al. Pricing Policies And Control of Tobacco in Europe (PPACTE) project: cross-national comparison of smoking prevalence in 18 European countries. Eur J Cancer Prev 2014; 23: 177-185.

35 Winter K. Hardcore smoking does not necessarily indicate hardening. Addiction 2014; 109: 681-682.

36 Gartner C, Scollo M, Marquart L, et al. Analysis of national data shows mixed evidence of hardening among Australian smokers. Aust NZ J Public Health 2012; 36: 408-414.

37 Clare P, Bradford D, Courtney RJ, et al. The relationship between socioeconomic status and "hardcore" smoking over time - greater accumulation of hardened smokers in low-SES than high-SES smokers. Tob Control 2014; 23: e133-e138.

38 Kulik MC, Glantz SA. Softening among U.S. smokers with psychological distress: more quit attempts and lower consumption as smoking drops. Am J Prev Med 2017; 53: 810-817.

39 Fagerström K. Determinants of tobacco use and renaming the FTND to the Fagerström Test for Cigarette Dependence. Nicotine Tob Res 2012; 14: 75-78.

40 Heatherton TF, Kozlowski LT, Frevker RC, et al. Measuring heaviness of smoking: using self-reported time to the first cigarette of the day and number of cigarettes smoked per day. Br J Addict 1989; 84: 791-799.

41 Gorber SC, Schofield-Hurwitz S, Hardt J, et al. The accuracy of self-reported smoking: a systematic review of the relationship between self-reported and cotinine-assessed smoking status. Nicotine Tob Res 2009; 11: 12-24. 